\title{
A comparative study of laryngeal view and pressor response by using three different blades- Macintosh, miller and Mccoy laryngoscopes
}

\author{
Gaurav Dwivedi ${ }^{1}$, Lalit Gupta ${ }^{2}$ * \\ ${ }^{\mathbf{1}}$ Associate Professor, ${ }^{\mathbf{2}}$ Assistant Professor, Dept. of Anaesthesia, ${ }^{\mathbf{1}}$ Santosh Medical College, Ghaziabad, ${ }^{\mathbf{2}}$ Maulana Azad Medical \\ College and Hospital, Delhi, India \\ *Corresponding Author: Lalit Gupta \\ Email: lalit.doc@gmail.com
}

Received: $3^{\text {rd }}$ October, 2018

Accepted: $13^{\text {th }}$ November, 2018

\begin{abstract}
Maintenance of airway during anaesthesia is very important to anaesthesiologist. A prospective, randomized study was conducted in 90 patients (ASA-I \& II) posted for various surgeries under general anaesthesia with endotracheal intubation to evaluate differences in glottic view, attempts and duration of laryngoscopy and intubation attempts along with hemodynamic variability associated with the three blades- Macintosh, McCoy and Miller laryngoscope blade. Patients were randomly allocated in three groups. In first group laryngoscopy was done with Macintosh blade, in second group with Miller blade, in third group with McCoy blade.

In this study it was found that McCoy laryngoscope is distinctly superior to the Macintosh and Miller with less hemodynamic changes and better glottic visualization. Degree of difficulty in intubation was more with Miller blade in comparison to Macintosh and McCoy blade which is statistically significant (p value $<0.001$ ).
\end{abstract}

Keywords: Cormack lehane grade, Macintosh blade, McCoy blade, Miller blade, Degree of difficulty in intubation.

\section{Introduction}

The major responsibility of the anaesthesiologist towards the patient is the provision of patent airway; the most vital element is providing on intact functional respiration. Endotracheal intubation comprises part of general anaesthetic technique in most of the cases. Although laryngoscope was invented in $19^{\text {th }}$ century, the names most widely associated with it are Magill, who borrowed his design from that from an otolaryngologist. ${ }^{1-3}$ There blades have now become the fold standard against which other blades and intubation techniques are judged.

Failed and difficult endotracheal intubation remains an important cause of morbidity and mortality in anaesthesia. Incidence of difficult intubation and failed intubation due to anatomical distortion of larynx is $1-3 \%$ \& $0.5-2 \%$ respectively cases and failure in 0.5 $2 \%$ of cases. ${ }^{4}$

Laryngoscopes are used to visualized the larynx and adjacent structures most commonly for the purpose of inserting tube into the tracheobronchial tree. They range from simple rigid laryngoscope to complex fiberoptic apparatus to visualize the larynx. Difficult laryngoscopy is defined as inability to visualized beyond the epiglottis, by a routine laryngoscope ${ }^{5}$ (Macintosh Laryngoscope) with the patient head and neck in optimal position. When laryngoscopy proves difficult, the force applied also increased accordingly. The main causes are forward displacement of larynx, prominent teeth and backward displacement of tongue. In many cases, it is possible to visualize the epiglottis but difficult to elevate it.
If a device can improve the view of laryngoscopy, it will be a valuable aid to laryngoscopy and intubation various types of blades can be used. Variety of blades have been designed from time to time and modified versions introduced in clinical practice to overcome these problems. The McCoy laryngoscope blade is a modification of Macintosh laryngoscope blade to facilitate tracheal tube placement in case of nonvisualization of larynx. ${ }^{6}$ The hinged blade controlled by a lever on the handle of laryngoscope allows elevation of epiglottis and resulting in application of lesser forces. ${ }^{7,8}$ In some studies, the force exerted and degree of head elevation/extension were found less with straight blade i.e., Miller laryngoscope compared to Macintosh blade with improvement of laryngeal view. ${ }^{9,10}$

Laryngoscopy is known to have profound cardiovascular effects. ${ }^{11,12}$ These include the increase in blood pressure and increase in heart rate. ${ }^{13,14}$ The major cause for this is believed to arise from stretching of Supraglottic and para-pharyngeal region by laryngoscope blade resulting in increase in catecholamine secretion. ${ }^{15,16}$ Hence, we found it worthy to assess laryngeal view and pressor response by using three different blades - Macintosh, McCoy and Miller laryngoscopes.

\section{Materials and Methods}

After getting approval from our Institutional Review Board cum ethical committee board, this comparative study was conducted in 90 adult patients (ASA group I \& II) of either sex of age 18 years and above with Mallampatti scores I and II scheduled for 
elective surgery. Patients excluded from the study were having cardiac disease, with ASA group III or more and all patients with MP score III or more. Patients with cervical spine injury or disability, patients with risk of aspiration such as full stomach, pregnancy, and bowel obstruction were also excluded from study.

Patients were randomly divided into 3 groups of 30 patients each.

Group I- Macintosh Blade

Group II- Miller Blade

Group III-McCoy blade

All the patients were premedicated with midazolam $(0.02 \mathrm{mg} / \mathrm{kg})+$ Fentanyl $(2 \mu \mathrm{g} / \mathrm{kg})$ and Ondansetron $(0.08 \mathrm{mg} / \mathrm{Kg})$ before induction of anaesthesia. After preoxygenation for 3 mins, all the patients were induced with Propofol $(2 \mathrm{mg} / \mathrm{kg})$ followed by succinylcholine $(1-2 \mathrm{mg} / \mathrm{Kg})$. The various variables like heart rate, blood pressure (systolic and diastolic), mean arterial pressure, $\mathrm{SPO}_{2}$ were recorded before induction of base line values with continuous ECG (Lead II) recording.

Group I- Laryngoscopy was done by using Macintosh laryngoscope (appropriate size blade) taken as standard for laryngoscopy. The Macintosh blade has a smooth gentle curve that extends to the tip there is a flange at the left to push the tongue out of way. In the cross section, the tongue web and flange form a reverse Z. (Fig. 1)

Group II - laryngoscopy was done by using a Miler straight blade (appropriate size) the side of the flange is reduced to minimize trauma and the curve at the beak or tip is extended to improve lifting of the epiglottis. In the cross section, the flange, web and tongue from a $\mathrm{C}$ with the top fattened. (Fig. 2)

Group III - laryngoscopy was done by using a McCoy laryngoscope (appropriate size). The distal end is hinged so the tip is movable. A lever is attached to the proximal end of blade. When the lever is pushed towards the handle the tip of the blade is flexed, ordinarily without use of lever the McCoy blade can also be used as ordinary blade. (Fig. 3)

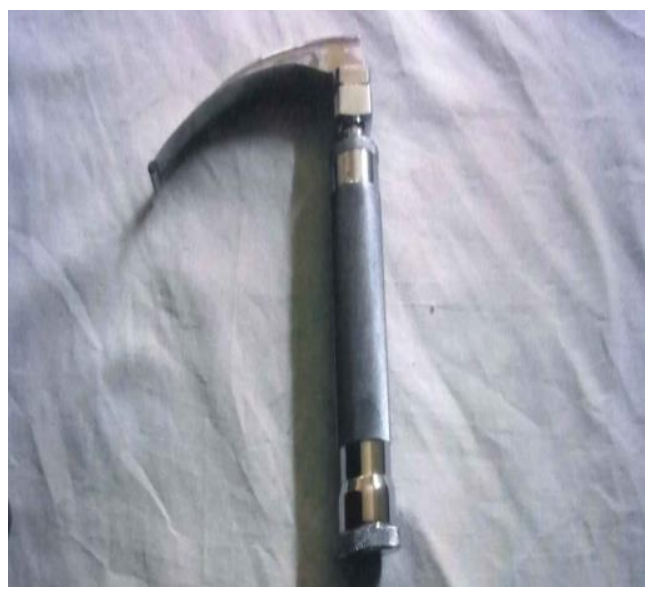

Fig. 1: Macintosh laryngoscope

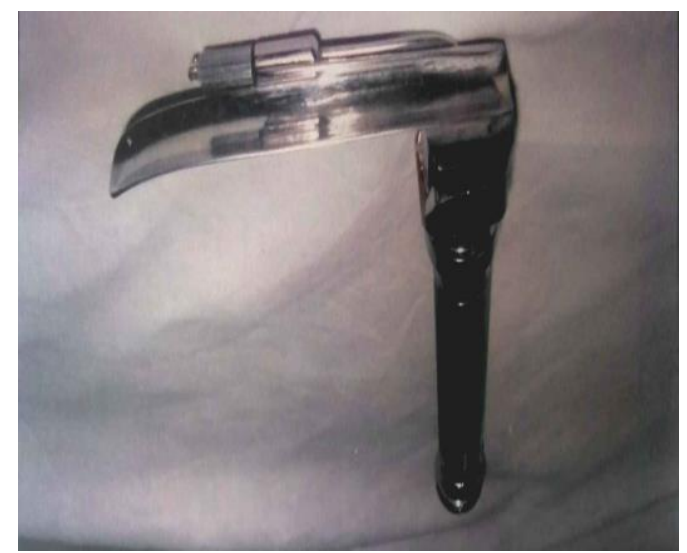

Fig. 2: Miller laryngoscope

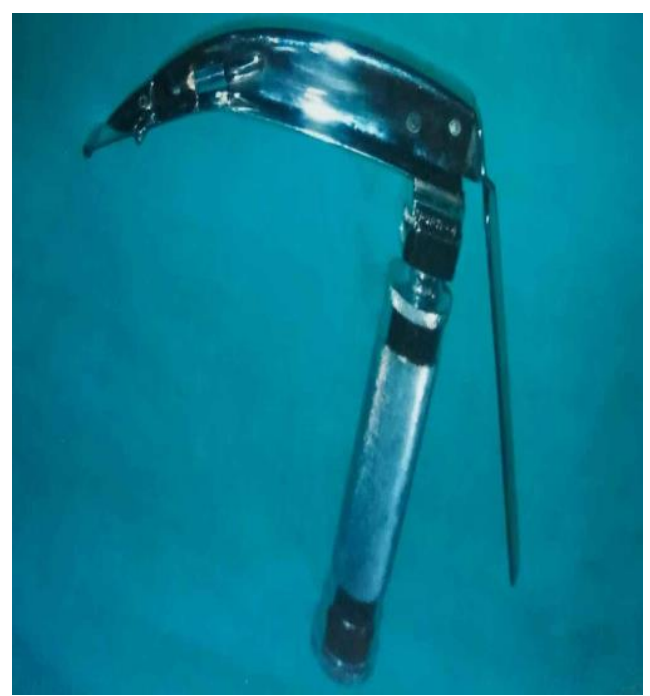

Fig. 3: McCoy laryngoscope

\section{Parameters Assessed}

Position of the patient was remained neutral in the beginning. A donut of $5 \mathrm{~cm}$ height was placed below head and extension was done if laryngoscopy could not be performed in the neutral position.

The laryngeal view was graded and noted by the Cormack-Lehane grading system. The duration of laryngoscopy (the time interval noted between mouth opening to the visualization of larynx) and duration of intubation (time interval between visualization of larynx to insertion of appropriate size tube) was noted. Number of laryngoscopic attempt and failure to intubate was noted. Change of blade was required in any case was noted.

Haemodynamic variables like heart rate, blood pressure, mean arterial pressure change in $\mathrm{SpO}_{2}$ level more than $5 \%$ of base line value and any arrhythmia, ectopic beat during procedure were recorded at $1 \mathrm{~min}$, $2 \mathrm{~min}$, 5min, and $10 \mathrm{~min}$ after intubation. Any complication during the procedure was recorded in the same manner.

Paired t-test was used for intra group comparisons while unpaired t-test was used for intergroup 
comparisons, a ' $p$ ' value $<0.05$ was taken as indicative of statistical significance. The t-value is the calculated difference represented in units of standard error. The greater the magnitude of ' $t$ ' (it can be either positive or negative), the greater the evidence against the null hypothesis that there is no significant difference. The closer $\mathrm{t}$ is to 0 , the more likely there isn't a significant difference. Changes in all the various parameters recorded between the three groups were analysed by the following statistical method.

Mean the arithmetic mean $\mathrm{X}$ is defined as $\sum x / n$ $\sigma \mathrm{n}^{-1}=\sqrt{\sum x^{2}}-\left(\sum x^{2}\right) / n$

n-1

Where, $\sigma \mathrm{n}^{-1}=$ standard deviation;

$\sum x=$ total sum of all values $; \mathrm{n}=$ the number of values.

\section{Results}

1. The three groups were similar with respect to their demographic profiles (Table 1)

( $\mathrm{p}$ value $>0.05)$.

Table 1: Demography characteristics

\begin{tabular}{|l|c|c|c|}
\hline \multicolumn{1}{|c|}{ Parameters } & $\begin{array}{c}\text { Group I } \\
\text { (Macintosh) }\end{array}$ & Group II (Miller blade) & $\begin{array}{c}\text { Group III (Mc Coy } \\
\text { blade) }\end{array}$ \\
\hline No. of Patients & 30 & 30 & 30 \\
\hline Age (Yrs) & & & \\
Mean \pm SD & $31.3 \pm 10.2$ & $33.4 \pm 3.36$ & $31.73 \pm 13.86$ \\
Range & $18-60$ & $18-60$ & $18-60$ \\
\hline Weight (Kgs) & $53.9 \pm 9.5$ & $51.23 \pm 7.6$ & $53.63 \pm 8.9$ \\
Mean \pm SD & & & $14(46.6)$ \\
\hline Sex (\%) & $15(50.0)$ & $14(46.6 .0)$ & $16(53.3)$ \\
Male & $15(50.0)$ & $16(53.3)$ & \\
Female & &
\end{tabular}

p > 0.05 Not Significant

2. With regards to Mallampatti class, head position and Cormark-Lehane $(\mathrm{C} / \mathrm{L})$ grading Table 2 shows:

i. In group III (McCoy group - 63.3\%) patients in neutral position and least in group II (Miller group - 26.6\%) had successful laryngoscopy. This shows doing laryngoscopy in neutral position is easier in group III as compared to other 2 groups. ii. The extended position of head for laryngoscopy was required maximum in group II (Miller group) $73.3 \%$ and least in group III (McCoy group) $36.6 \%$.

iii. Group III (McCoy) has highest incidence of $\mathrm{C} / \mathrm{L}$ grade I (83.3\%) as compared $66.6 \%$ of group I and $36.6 \%$ of group II. With C/L grade III was only found in group II in $10 \%$ cases but not in group I and III.

Table 2: Mallampatti class, head position and cormark-lehane grading

\begin{tabular}{|l|c|c|c|c|c|c|}
\hline \multirow{1}{*}{ Parameters } & \multicolumn{2}{c|}{$\begin{array}{c}\text { Group I } \\
\text { (Macintosh) } \\
\text { (30) }\end{array}$} & \multicolumn{2}{c|}{$\begin{array}{c}\text { Group II } \\
\text { (Miller blade) } \\
\text { (30) }\end{array}$} & \multicolumn{2}{c|}{$\begin{array}{c}\text { Group III } \\
\text { McCoy blade) } \\
\text { (30) }\end{array}$} \\
\cline { 2 - 7 } & $\mathbf{N}$ & $\mathbf{\%}$ & $\mathbf{N}(\mathbf{3 0})$ & $\mathbf{\%}$ & $\mathbf{N}$ & $\mathbf{\%}$ \\
\hline MP & 21 & 70 & 20 & 66.6 & 21 & 70 \\
I & 9 & 30 & 10 & 33.3 & 9 & 30 \\
II & 13 & 43.3 & 8 & 26.6 & 19 & 63.3 \\
\hline Head Position & 17 & 56.6 & 22 & 73.3 & 11 & 36.6 \\
Neutral & & & & & & \\
Extended & 20 & 66.6 & 11 & 36.6 & 25 & 83.3 \\
\hline C-L Grading & 10 & 33.3 & 16 & 53.3 & 5 & 16.6 \\
Grade I & 0 & 0 & 3 & 10 & 0 & 0 \\
Grade II & & & & & \\
Grade III &
\end{tabular}

3. With regards to mean duration of laryngoscopy, mean time taken for intubation and change of blade, Table 3 shows: i. Mean duration of laryngoscopy is $19.3 \pm 4.2 \mathrm{sec}$ in group I, is comparable to $21.5 \pm 2.23$ of group II $(\mathrm{p}>0.05)$ but it is $15.2 \pm 3.2 \mathrm{sec}$ in group III i.e., 
McCoy group is statistically significant $(\mathrm{p}<0.05)$ than group I and group II.

ii. Mean time to place the tube was significantly less in group III i.e. $5.1+1.6 \mathrm{sec}$ as compared to group I and II and maximum time was $6.8 \pm 9.83 \mathrm{sec}$ in group II, which was statistically significant $(\mathrm{p}<0.05)$.

iii. 3 cases in group II (Miller blade) needed change of alternative blade but not in group I and III. These cases were excluded from the study.

Table 3: Mean duration of laryngoscopy, intubation \& change of blade

\begin{tabular}{|l|c|c|c|}
\hline \multicolumn{1}{|c|}{ Mean \pm SD } & Group I & Group I & Group I \\
\hline Duration of laryngoscopy in seconds & $19.3 \pm 4.2$ & $21.5 \pm 2.23$ & $15.2 \pm 3.1$ \\
\hline Duration of intubation in seconds & $6.3 \pm 2.8$ & $6.8 \pm 9.83$ & $5.1 \pm 1.6$ \\
\hline Change of blade require & 00 & 03 & 00 \\
\hline
\end{tabular}

\section{Hemodynamic Parameters}

4. Changes in heart rate, Systolic, Diastolic and Mean BP (Table 4-5) occurring during laryngoscopy are highly significant $(\mathrm{p}<0.001)$ in all the groups in 1 and 2 min. The changes are less significant in group III at $5 \& 10 \mathrm{~min}$.

i. In comparison between the groups the Heart rate changes during laryngoscopy were less in group III as compared to group II $(\mathrm{p}<0.001)$ and group I $(\mathrm{p}<0.01)$ (statistically significant). These changes continued till 10min between groups III and group I \& II. However, these changes were not so much significant between groups II \& I. ii. In comparison between the groups the systolic blood pressure changes are comparable between group I \& II ( $>>0.05)$ at $1 \mathrm{~min}$. but group III has less marked increase in blood pressure in comparison to group A $(\mathrm{p}<0.05)$ and group B $(\mathrm{p}<0.001)$.

iii. In comparison between the group all the groups have comparable changes in Diastolic blood pressure ( $p>0.05$ statistically insignificant).

iv. In comparison between the group the changes in MAP are comparatively less in group III as compared to group I \& II $(\mathrm{p}<0.01)$ but the changes are insignificant between the group I \& II ( $>0.05)$ at $1^{\text {st }}, 5^{\text {th }}$ and $10^{\text {th }}$ min after intubation.

Table 4: Hemodynamic comparison

\begin{tabular}{|c|c|c|c|}
\hline Parameter & Group I & Group II & Group IIII \\
\hline \multirow{2}{*}{$\begin{array}{l}\text { Heart Rate } \\
\text { (beat/min) } \\
\mathrm{HR}_{0}\end{array}$} & $79.07+16.01$ & $80.6+8.52$ & $84.23+12.94$ \\
\hline & $\begin{array}{c}104.9 \pm 12.9 \\
\mathrm{t}=10.8, \mathrm{p}<0.001\end{array}$ & $\begin{array}{c}107.3 \pm 11.76 \\
\mathrm{t}=15.5, \mathrm{p}<0.001\end{array}$ & $\begin{array}{c}97.53 \pm 16.1 \\
t=8.6, p<0.001\end{array}$ \\
\hline $\mathrm{HR}_{1}$ & $\begin{array}{c}101.9 \pm 12.2 \\
\mathrm{t}=10.6, \mathrm{p}<0.001\end{array}$ & $\begin{array}{c}103.3 \pm 11.93 \\
\mathrm{t}=12.8, \mathrm{p}<0.001\end{array}$ & $\begin{array}{c}95.1 \pm 15 \\
\mathrm{t}=8.1, \mathrm{p}<0.001\end{array}$ \\
\hline $\mathrm{HR}_{2}$ & $\begin{array}{c}96.07 \pm 11.74 \\
t=7.2, p<0.001\end{array}$ & $\begin{array}{c}97.07 \pm 19.83 \\
\mathrm{t}=12.1, \mathrm{p}<0.001\end{array}$ & $\begin{array}{c}91.47 \pm 14.57 \\
t=5.4, \mathrm{p}<0.001\end{array}$ \\
\hline $\mathrm{HR}_{5}$ & $\begin{array}{c}90.07 \pm 11.94 \\
t=5.4, p<0.001\end{array}$ & $\begin{array}{c}96 \pm 11.89 \\
\mathrm{t}=8.3, \mathrm{p}<0.001\end{array}$ & $\begin{array}{c}88.27 \pm 14.29 \\
t=4.1, p<0.001\end{array}$ \\
\hline \multirow{2}{*}{$\begin{array}{l}\text { Systolic BP } \\
(\mathbf{m m H g}) \\
\mathrm{SBP}_{0}\end{array}$} & $116.53 \pm 22.33$ & $120.0 \pm 11.3$ & $117.6 \pm 10.91$ \\
\hline & $\begin{array}{c}149 \pm 12.86 \\
\mathrm{t}=21.3, \mathrm{p}<0.001\end{array}$ & $\begin{array}{c}148 \pm 12.1 \\
\mathrm{t}=13.5, \mathrm{p}<0.001\end{array}$ & $\begin{array}{l}134.9 \pm 13.15 \\
t=9, p<0.001\end{array}$ \\
\hline $\mathrm{SBP}_{1}$ & $\begin{array}{c}143.7 \pm 9.19 \\
t=21, p<0.001\end{array}$ & $\begin{array}{c}145.1 \pm 12.2 \\
\mathrm{t}=13.5, \mathrm{p}<0.001\end{array}$ & $\begin{array}{c}129.9 \pm 24.61 \\
t=9.1, p<0.001\end{array}$ \\
\hline $\mathrm{SBP}_{2}$ & $\begin{array}{c}136.3 \pm 7.5 \\
\mathrm{t}=7.2, \mathrm{p}<0.001\end{array}$ & $\begin{array}{c}139.4+9.5 \\
\mathrm{t}=11.2, \mathrm{p}<0.001\end{array}$ & $\begin{array}{c}126.5 \pm 12.48 \\
t=6.0, p<0.001\end{array}$ \\
\hline $\mathrm{SBP}_{5}$ & $\begin{array}{c}130.5 \pm 10.87 \\
t=5.4, p<0.001\end{array}$ & $\begin{array}{c}135 \pm 9.97 \\
\mathrm{t}=10.4, \mathrm{p}<0.001\end{array}$ & $\begin{array}{c}123.7 \pm 11.6 \\
t=4.5, p<0.01\end{array}$ \\
\hline \multirow{2}{*}{ 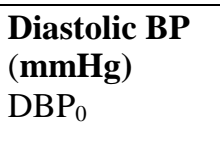 } & $78.46 \pm 7.2$ & $78.41 \pm 7.49$ & $76 \pm 8.05$ \\
\hline & $\begin{array}{c}90 \pm 6.0 \\
\mathrm{t}=8.8, \mathrm{p}<0.001\end{array}$ & $\begin{array}{c}98 \pm 7.1 \\
\mathrm{t}=9.3, \mathrm{p}<0.001\end{array}$ & $\begin{array}{c}84.9+6.8 \\
t=9, p<0.001\end{array}$ \\
\hline $\mathrm{DBP}_{1}$ & $\begin{array}{c}88.4 \pm 6.0 \\
t=9, p<0.001\end{array}$ & $\begin{array}{c}87.2 \pm 6.7 \\
t=9.5, p<0.001\end{array}$ & $\begin{array}{c}83.9 \pm 6.9 \\
\mathrm{t}=8.1, \mathrm{p}<0.001\end{array}$ \\
\hline
\end{tabular}




\begin{tabular}{|l|c|c|c|}
\hline $\mathrm{DBP}_{2}$ & $\begin{array}{c}84.93 \pm 4.8 \\
\mathrm{DBP}_{5}\end{array}$ & $\begin{array}{c}84.6 \pm 5.2 \\
\mathrm{t}=6.4, \mathrm{p}<0.001\end{array}$ & $\begin{array}{c}80.0 \pm 7.1 \\
\mathrm{t}=6.2, \mathrm{p}<0.001\end{array}$ \\
\cline { 2 - 4 } $\mathrm{DBP}_{10}$ & $82.3 \pm 6.51$ & $80 \pm 7.1$ & $78.7 \pm 7.3$ \\
$\mathrm{t}=5.4, \mathrm{p}<0.01$ & $\mathrm{t}=4.4, \mathrm{p}<0.01$ & \\
\hline $\begin{array}{l}\text { Mean BP } \\
(\mathbf{m m H g})\end{array}$ & & & \\
$\mathrm{MBP}_{0}$ & $92.46 \pm 7.7$ & $92.17 \pm 8.55$ & $89.87 \pm 8.6$ \\
\cline { 2 - 4 } & $108 \pm 6.7$ & $109.7 \pm 7.79$ & $101.9 \pm 8.5$ \\
$\mathrm{MBP}_{1}$ & $\mathrm{t}=15.6, \mathrm{p}<0.001$ & $\mathrm{t}=13.5, \mathrm{p}<0.001$ & $\mathrm{t}=11.9, \mathrm{p}<0.001$ \\
\cline { 2 - 4 } & $107.07 \pm 6.5$ & $106.5 \pm 8.2$ & $100.79 \pm 7.9$ \\
$\mathrm{MBP}_{2}$ & $\mathrm{t}=10.4, \mathrm{p}<0.001$ & $\mathrm{t}=14.6, \mathrm{p}<0.001$ & $\mathrm{t}=8.9, \mathrm{p}<0.00$ \\
\cline { 2 - 4 } & $99.13 \pm 17.5$ & $103.1 \pm 6.37$ & $95.5 \pm 8.48$ \\
$\mathrm{MBP}_{5}$ & $\mathrm{t}=8.9 \mathrm{p}<0.001$ & $\mathrm{t}=12.8, \mathrm{p}<0.001$ & $\mathrm{t}=5.6, \mathrm{p}<0.001$ \\
\cline { 2 - 4 } & $98.5 \pm 7.33$ & $100.1 \pm 6.4$ & $93.7 \pm 8.33$ \\
$\mathrm{MBP}_{10}$ & $\mathrm{t}=6.24, \mathrm{p}<0.01$ & $\mathrm{t}=9.1, \mathrm{p}<0.001$ & $\mathrm{t}=4.6, \mathrm{p}<0.01$ \\
\hline
\end{tabular}

Table 5: Inter group comparison of " $p$ value and $t$ value"

\begin{tabular}{|c|c|c|c|}
\hline Parameter & Group I \& II & Group II \& III & Group I \& III \\
\hline HR 1 min & $\begin{array}{l}t=1.86 \\
p>0.05\end{array}$ & $\begin{array}{c}t=6.4 \\
p<0.001\end{array}$ & $\begin{aligned} \mathrm{t} & =3.8 \\
\mathrm{p} & <0.01\end{aligned}$ \\
\hline $5 \min$ & $\begin{array}{l}t=2.3 \\
p<0.05\end{array}$ & $\begin{array}{c}\mathrm{t}=6.6 \\
\mathrm{p}<0.001\end{array}$ & $\begin{array}{c}\mathrm{t}=3.4 \\
\mathrm{p}<0.01\end{array}$ \\
\hline $10 \min$ & $\begin{array}{c}\mathrm{t}=2.5 \\
\mathrm{p}<0.05\end{array}$ & $\begin{array}{c}\mathrm{t}=5.5 \\
\mathrm{p}<0.001\end{array}$ & $\begin{array}{c}\mathrm{t}=2.1 \\
\mathrm{p}<0.01\end{array}$ \\
\hline SBP 1 min & $\begin{array}{c}t=0.2 \\
p>0.05\end{array}$ & $\begin{array}{c}t=6.9 \\
p<0.001\end{array}$ & $\begin{array}{c}\mathrm{t}=2.4 \\
\mathrm{p}<0.05\end{array}$ \\
\hline $5 \mathrm{~min}$ & $\begin{array}{l}\mathrm{t}=2.9 \\
\mathrm{p}<0.05\end{array}$ & $\begin{array}{c}t=7.5 \\
p<0.001\end{array}$ & $\begin{array}{c}\mathrm{t}=3.1 \\
\mathrm{p}<0.01\end{array}$ \\
\hline $10 \mathrm{~min}$ & $\begin{array}{c}\mathrm{t}=2.4 \\
\mathrm{p}<0.05\end{array}$ & $\begin{array}{c}\mathrm{t}=4.4 \\
\mathrm{p}<0.001\end{array}$ & $\begin{array}{c}\mathrm{t}=1.3 \\
\mathrm{p}<0.01\end{array}$ \\
\hline DBP 1 min & $\begin{aligned} \mathrm{t} & =0.2 \\
\mathrm{p} & >0.05\end{aligned}$ & $\begin{array}{c}\mathrm{t}=1.2 \\
\mathrm{p}<0.05\end{array}$ & $\begin{array}{c}\mathrm{t}=0.5 \\
\mathrm{p}<0.05\end{array}$ \\
\hline $5 \mathrm{~min}$ & $\begin{array}{l}t=0.3 \\
p>0.05\end{array}$ & $\begin{array}{l}\mathrm{t}=1.6 \\
\mathrm{p}<0.05\end{array}$ & $\begin{array}{c}\mathrm{t}=0.9 \\
\mathrm{p}<0.05\end{array}$ \\
\hline $10 \min$ & $\begin{aligned} \mathrm{t} & =0.6 \\
\mathrm{p} & >0.05\end{aligned}$ & $\begin{array}{c}\mathrm{t}=0.8 \\
\mathrm{p}<0.05\end{array}$ & $\begin{array}{c}\mathrm{t}=0.2 \\
\mathrm{p}>0.05\end{array}$ \\
\hline MBP 1 min & $\begin{aligned} t & =0.2 \\
p & >0.05\end{aligned}$ & $\begin{array}{c}\mathrm{t}=3.3 \\
\mathrm{p}<0.05\end{array}$ & $\begin{array}{c}\mathrm{t}=3.0 \\
\mathrm{p}<0.05\end{array}$ \\
\hline $5 \mathrm{~min}$ & $\begin{array}{l}t=1.5 \\
p<0.05\end{array}$ & $\begin{array}{c}\mathrm{t}=4.8 \\
\mathrm{p}<0.01\end{array}$ & $\begin{array}{c}\mathrm{t}=2.0 \\
\mathrm{p}<0.05\end{array}$ \\
\hline $10 \mathrm{~min}$ & $\begin{array}{c}\mathrm{t}=1.7 \\
\mathrm{p}<0.05\end{array}$ & $\begin{array}{c}\mathrm{t}=2.8 \\
\mathrm{p}<0.05\end{array}$ & $\begin{array}{c}\mathrm{t}=0.4 \\
\mathrm{p}<0.05\end{array}$ \\
\hline
\end{tabular}

\section{Discussion}

In due course of development of anaesthesia, so many new techniques of intubation and Supraglottic devices have been developed from time to time but the gold standard has been remained the direct laryngoscopy and endotracheal placement of the tube. In this present study we compared the Macintosh Miller and McCoy blade for the laryngoscopic view position of head, mean duration of laryngoscopy, intubation and haemodynamic changes with the use of blade.

The sex distribution (Table 1) in the study was nearly identical and statistically insignificant $(p>0.05)$ in all the three groups. The patients selected for this study were above 18yrs age. It was observed (Table 2) that the maximum number were below 40yrs in all the groups $60 \%, 56.6 \%$ and $60 \%$ respectively with mean age of patients (Table 3) 31.43+10.2, 33.4+13.63 and $31.73 \pm 13.86(p>0.05)$. The patient selection with regard to age in our study was similar to that of the landmark studies done by JP Tuckey ${ }^{7}$ and McCoy EP ${ }^{17}$ in 1996 as comparison between Macintosh Vs McCoy and in 1997 between Macintosh Vs Miller Vs McCoy by Nishiyama ${ }^{18}$ and Konishi A, Sakai ${ }^{19}$ et al.

The mean weight $(53.9 \pm 9.5, \quad 51.23 \pm 7.6$ and $53.63 \pm 8.9)$ and Mallampatti Score (MP grade-1: $70 \%$, $66.6 \%$ and $70 \%$ ) of patients in group I, II and III in the 
present study were also not statistically significant ( $>0.05)$.

Previous studies done by E.P. $\mathrm{McCoy}^{17}$ and T. Uchida $^{20}$ (Macintosh s McCoy) and J.P. Tuckey ${ }^{7}$ and Sakai $\mathrm{T}^{21}$ et al. (Macintosh Vs Miller Vs McCoy) like our study also could not ascertain any correlation with the parameters with their results and demographic data including age, sex, weight and ASA physical status of the patient

Our anaesthesia technique of premedication, induction and relaxation followed by laryngoscopy with appropriately chosen blade was in accordance with most other studies, were a similar technique was used. The position of the patient at the time of intubation in neutral position best ease was recorded, whether it was neutral position or head was extended by putting $5 \mathrm{~cm}$ donut below head as per protocol decision we were able to do the laryngoscopy and intubation in the neutral position in $63.3 \%$ patients in McCoy group as compared to $43.3 \%$ of Macintosh group and $26.6 \%$ of Miller group.

The study showed that the McCoy laryngoscope improved laryngeal visualization in patients with the neck stabilized in neutral position. The McCoy laryngoscope is designed with hinged tip so the difficult laryngeal visualization may be improved with lifting the epiglottis, especially in patients with neck fixed in neutral position. This laryngoscope can improve the laryngeal view. Our results are in consistent with E.P. McCoy \& Mirakhur ${ }^{22-24}$ (Macintosh Vs McCoy), J.Uchida $^{20}$ and M.C. Gerling ${ }^{25}$ (Macintosh Vs McCoy) and subsequently with Saki T, Konishi $\mathrm{A}^{21}$ and Nishiyama, Higashizawa ${ }^{19,21}$ (Macintosh Vs Miller Vs McCoy). These studies also supported that McCoy laryngoscope provides better and improved glottic view in normal as well as in difficult airway scenarios.

The best visualisation i.e., Cormack-Lehane group I was found in $83.3 \%$ of case in McCoy as compared to Miller and Macintosh group. This is due to the fact that when levering laryngoscope tip of the McCoy blade placed between the base of tongue and the epiglottis, it moves the tip forward and convert the grade II or grade III into grade I or II intubation due to levering action. This can be done without having to exert external pressure on larynx by an assistant. The tip of the laryngoscope blade can also be placed posterior to epiglottis as with conventional straight blade and give a good view of larynx by lifting the tip but without having to exert the same degree of force as with conventional Miller straight blade.

D.A. Gabbot ${ }^{26}$ also reported in their study in 1996 that the McCoy laryngoscope significantly improves the in identification of glottis structures inpatients wearing a rigid, cervical neck collar and its use is to be encouraged if attempts are made to intubate the trachea of patients with potential cervical spine injuries when removal of cervical collar is not practical or possible.
In 2003, Jose J Arino conducted a study between different laryngoscope blade and reported the McCoy blade was used in neutral position when the view of larynx was grade I, when needed the tip of the McCoy blade was elevated and the view of the larynx was significantly improved by one or two grade in $80.6 \%$ of patients and remain unchanged in $19.4 \%$ of patients with Cormack-Lehane II and III and none in CormackLehane grade IV laryngoscopy.

In our study, best intubation results were obtained with the curved McCoy and Macintosh blade $(\mathrm{p}<0.001)$ as curved blade provide more room in oropharynx to manoeuvre the endotracheal tube and give better intubation conditions then other straight blades. We also observed that the mean duration of laryngoscopy and mean duration for endotracheal tube placement into the trachea was $15.2 \pm 3.1 \mathrm{sec}$ and $5.1 \pm 1.6 \mathrm{sec}$ in McCoy group that was significantly less as compared to Macintosh and Miller laryngoscopic blade. This was due to a possible reason that a better visualization of larynx and elevation of the epiglottis gives more space to the endotracheal tube as compared to the straight Miller blade.

While comparing all the three groups for haemodynamic changes surprisingly the statistically $(p<0.01)$ least haemodynamic changes were evident in group III i.e., McCoy group as compared to group I \& II. This may be due to the fact that McCoy blade requires less force than Macintosh and Miller blade for visualisation of larynx, which limits sympathetic activation response. In 1995 Ep McCoy and R.K. Mirakhur ${ }^{23}$ reported in their study the pressure response to laryngoscopy (changes in heart rate and blood pressure) with use of McCoy laryngoscope were even less than found with awake fiberoptic intubation. The observations made in our study relating to haemodynamic changes in group III are in accordance with those made by J.P. Tucky ${ }^{7}$ and Jose J Arino. ${ }^{27}$ Our observations are in contrast to those made by T.M. Cook, ${ }^{7}$ who did not report any improved laryngeal view and less haemodynamic changes with use of McCoy blade.

Average fall in $\mathrm{O}_{2}$ saturation was not $>5 \%$ in any patient in any group in our study. In the present study average fall in $\mathrm{O}_{2}$ saturation was not more than $5 \%$ from the base line (minimum 95\%) as all the patients were preoxygenated with $100 \% \mathrm{O}_{2}$. Regarding the ECG changes, there was no abnormality detected other than sinus tachycardia as no marked hypoxia occurred in any patients.

\section{Conclusion}

Based on the findings of our result, the McCoy laryngoscope is distinctly superior to the Macintosh and Miller blade for use of general anaesthesia in elective surgery with less hemodynamic changes and better glottic visualization with improved tracheal intubating conditions. 


\section{References}

1. Magill IW. An improved laryngoscope for anaesthetists. Lancet. 1926;1:500.

2. Magill IW. Endo-Tracheal anaesthesia. Proceedings of Royal society of Medicine. 1928;22:83-8.

3. Macintosh RR. A new laryngoscope. Lancet. 1943;1:205.

4. Latto IP. Management of difficult intubation. In Latto IP, Rosen M. (Eds). Difficulties in Tracheal intubation. London: Bailliere Tindall, 1987;99:99-141.

5. Crosby ET, Cooper RM, Douglas MJ, Doyle DJ, Hung OR, Labrecque $\mathrm{P}$, et al. The unanticipated difficult airway with recommendations for management. Can J Anaesth. 1998;45:757-776.

6. McCoy EP, Austin BA, Mirakhur RK, Wong KC. A new device for measuring and recoding the forces applied during laryngoscopy. Anaesth. 1995;50:139-143.

7. Cook TM, Tuckey JP. A comparison between the Macintosh and the MacCoy Laryngoscope blades. Anaesth. 1996;51:977-890.

8. Pritchard C. Comparison of the Macintosh and McCoy laryngoscope blades. Anaesthesia. 1997; 52: 185-6.

9. Hastings RH, Hon ED, Nghiem C, Wahrenbrock EA. Force and torque vary between laryngoscopists and laryngoscope blades. Anesth Analg. 1996;82:462-468.

10. Hawkins M, Groom P. Comparison of the Macintosh and McCoy laryngoscope blades. Anaesthesia. 197;52:280281.

11. Hamayasu Y. Cardiovascular changes produced by endotracheal intubation during general anaesthesia. Jpn J Anesth. 1974;23:533

12. Hemodynamic response to intubation with Macintosh and McCoy blades. Rev Esp Anestesiol Reanim. 1996;43:177179.

13. Castillo J, Casano J, Escolano F, Arilla M. Cardiocirculatory response to laryngoscpy. Comparative study between Macintosh and McCoy laryngoscopes. Rev Espanestesiol Reanim 1996;43:219-221.

14. Norris TJ, Baysinger CL. Heart rate and blood pressure response to laryngoscopy: the influence of laryngocopic technique. Anaesthesiol. 1986;63:560.

15. Dodd RB, Sims WA, Bone DJ. Cardiac arrhythmias observed during anaesthesia. Sur. 1962;51:440.

16. Takii S, Tammisto T, Niukki p, Jattela A. effect of laryngoscopy and intubation on plasma catecholamine levels during intravenous induction of anaesthesia. $\mathrm{Br} \mathrm{J}$ Anaesth. 1972;44:1323.

17. McCoy EP, Mirakhur RK, Rafferty C, Bunting H, Austin BA. A comparison of the forces exerted during laryngoscopy. The Macintosh versus the McCoy blade. Anaesth. 1996;51:912-915.
18. Shimoda O, Ikuta Y, Isayama S, Sakamoto M, Terasaki H. Skin Vascomotor reflex induced laryngoscopy: comparison of the McCoy and Macintosh Blades. Br J Anaesth. 1997;79:714-718.

19. Nishiyama, Tomoki. "[Which laryngoscope is the most stressful in laryngoscopy; Macintosh, Miller, or McCoy?].” Masui. The Japanese journal of Anesthesiol. 1997;46(11):1519-1524.

20. Uchida T, Hikawa Y, Saito Y, Yadya K. The McCoy levering laryngoscope inpatients with limited neck extension. Can J Anaesth. 1997; 44: 674-6.

21. Sakai T, Konishi T, Nishiyama T, Higashizawa T, Bito H. A comparison of the grade of laryngeal visualization; the McCoy compared with the Macintosh and the Miller blade in adults. Masui.1998;47:998-1001.

22. McCoy EP, Mirakhur RK, McCloskey BV. A comparison of the stress response to laryngoscopy. The Macintosh Versus the McCoy blade. Anaesth. 1995;50:943-946.

23. McCoy EP, Mirakhur RK, Rafferty C, Bunting H, Austin BA. A comparison of the forces exerted during laryngoscopy. The Macintosh versus the McCoy blade. Anaesth. 1996;51:912-915.

24. McMarrow RC, Mirakhur RK. A new mirrored laryngoscope Anaesthesia. 2003; 58:998-1002.

25. Gerling MC, Davis DP, Hamilton RS, Morris GF, Vilke GM, Garfin SR, Hayden Sr. Effects of cervical spine immobilization technique and laryngoscope blade selection on an unstable cervical spine in a cadaver model of intubation. Ann Emerg Med. 2000;36:293-300.

26. Gaboot DA. Laryngoscopy using the McCoy laryngoscope after application of a cervical collar. Anaesth. 1996;51:812-814.

27. Arino JJ, Velasco JM, Gasco C, Lopez-Timoneda F. Straight blades improve visualization of the larynx while curved blades increase ease of intubation: a comparison of the Macintosh, Miller, McCoy, Belscope and LeeFiberview blades. Can J Anesth. 2003;50:501-506.

How to cite this article: Dwivedi G, Gupta L. A comparative study of laryngeal view and pressor response by using three different blades- Macintosh, miller and Mccoy laryngoscopes. Indian $\mathbf{J}$ Clin Anaesth. 2018;5(4):569-575. 